\title{
Лечение токсических побочных эффектов у пациентов с распространенным медуллярным раком щuтовидной железы ${ }^{1}$
}

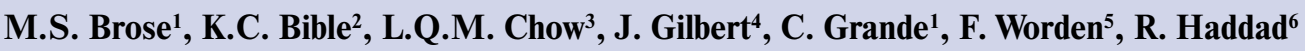 \\ ${ }^{\prime}$ Department of Otorhinolaryngology, Head and Neck Surgery and the Abramson Cancer Center, University of Pennsylvania, United States; \\ ${ }^{2}$ Mayo Clinic-Rochester, United States; \\ ${ }^{3}$ University of Washington, United States; \\ ${ }^{4}$ Vanderbilt University, United States; \\ ${ }^{5}$ University of Michigan, United States; \\ ${ }^{6}$ Dana-Farber Cancer Institute, United States \\ Контакты: Robert Haddad robert_haddad@dfci.harvard.edu
}

Большой прогресс в лечении распространенного медуллярного рака щитовидной железы за последние 5 лет достигнут благодаря одобрению 2 препаратов - вандетаниба и кабозантиниба. Действие этих ингибиторов протеинкиназ во многом совпадает и направлено на различные мишени, участвующие в патогенезе медуллярного рака щитовидной железы. Оба препарата имеют достаточно широкий ряд токсических побочных эффектов, таких как артериальная гипертензия, кровотечения, перфорация кишечника, диарея и другие нежелательные явления со стороны желудочно-кишечного тракта, поражения кожи и гипотиреоз. Кроме того, вандетаниб может вызывать удлинение интервала QT из-за взаимодействия с калиевыми ионными каналами клеток миокарда, а кабозантиниб - ладонно-подошвенный синдром. Связанные с лечением токсические эффекты возникают достаточно часто, могут быть очень тяжелыми и даже опасными для жизни. Следовательно, пациенты, получаюшие эти препараты в течение длительного времени, имеют весьма высокий риск развития побочных эффектов. В данной статье даны практические рекомендации по лечению побочных эффектов применения вандетаниба и кабозантиниба. Рекомендуемый нами подход основан на раннем выявлении побочных эффектов и их своевременном лечении на фоне прерывания терапии ингибиторами протеинкиназ или снижения их дозы, чтобы обеспечить как можно более длительное применение максимально допустимой для конкретного пациента дозы препарата и предотвратить ухудшение качества его жизни. На сегодняшний день отсутствуют рекомендации по выбору очередности применения вандетаниба и кабозантиниба, однако большинство пациентов получают оба эти препарата. Выбор терапии 1-й линии следует проводить в индивидуальном порядке после тщательной оценки потенциальных рисков и пользы. Часто этот выбор зависит от предпочтений врача и особенностей пациента, например наличия сопутствующих заболеваний. Поскольку многие специалисты могут быть незнакомы с тонкостями применения таких препаратов, как вандетаниб и кабозантиниб, мы рекомендуем проводить лечение пациентов с медуллярным раком щитовидной железы под контролем опытного, хорошо осведомленного специалиста, а также мультидисциплинарной бригады врачей.

Ключевые слова: кабозантиниб, медуллярный, метастатический, мультикиназный, CAPRELSA Risk Evaluation and Mitigation Strategy, вандетаниб

Для цитирования: Brose M.S., Bible K.C., Chow L.Q.M. et al. Лечение токсических побочных эффектов у пациентов с распространенным медуллярным раком щитовидной железы. Опухоли головы и шеи 2019;9(1):51-67.

DOI: $10.17650 / 2222-1468-2019-9-1-51-67$

\section{Введение}

Медуллярный рак щитовидной железы (МРЩЖ) редкая нейроэндокринная опухоль, которая развивается из парафолликулярных клеток (С-клеток) щитовидной железы, продуцирующих кальцитонин [1, 2]. Уровень кальцитонина >1000 пг/мл, как правило, свидетельствует о наличии прогрессирующего заболевания с отдаленными метастазами (в печени, легких, костях, лимфатических узлах и головном мозге) [1-3]. Точные данные о распространенности МРЩЖ до сих пор отсутствуют вследствие его редкости, однако известно, что заболеваемость составляет примерно 0,2 случая на 100 тыс. человек [4]. Поскольку приблизительно в $20 \%$ случаев МРЩЖ ассоциирован с синдромом множественной эндокринной неоплазии, всем пациентам с МРЩЖ рекомендовано пройти скрининг на наличие герминативных мутаций протоонкогена $R E T$, произошедших в ходе трансфекции [5]. При ранних

\footnotetext{
${ }^{1}$ Публикуется на русском языке с разрешения авторов. Оригинал: Brose M.S., Bible K.C., Chow L.Q.M. et al. Management of treatment-related toxicities in advanced medullary thyroid cancer. Cancer Treat Rev 2018;66:64-73. DOI: 10.1016/j.ctrv.2018.04.007.
} 
стадиях заболевания (I-III) 5-летняя выживаемость превышает $90 \%$, но в случае распространенного МРШЖ составляет <30\% [1]. На ранних стадиях МРЩЖ поддается хирургическому лечению, в то время как на поздних стадиях опухоль в основном неоперабельна и резистентна ко всем доступным на сегодня методам лечения, что создает необходимость разработки новых методов лечения для таких пациентов [1, 2].

\section{Мультикиназные uнгибиторы в лечении распространенных форм медуллярного рака щuтовидной железы}

Несмотря на то что терапия ингибиторами протеинкиназ (ИПК) не приводит к выздоровлению, эти препараты продолжают играть важную роль в лечении распространенных/метастатических форм МРЩЖ, которые сопровождаются клинической симптоматикой, прогрессируют или создают угрозу для жизни. На сегодняшний день 2 ИПК - вандетаниб (Капрелса ${ }^{\circledR}$; Sanofi Genzyme, Кембридж, США) и кабозантиниб (Кометрик $^{\circledR}$; Exelixis, Южный Сан-Франциско, США) - были рекомендованы для лечения МРШЖ в опубликованных руководствах [1, 2, 6, 7]. Кроме того, оба препарата были одобрены на основании результатов ключевых исследований III фазы по МРШЖ [6, 7]. Важно, что, поскольку в них принимали участие разные группы пациентов, а также имелись различия в организации (возможности перехода пациентов в группу препарата из группы плацебо при прогрессировании заболевания), прямое сравнение их результатов (табл. 1) невозможно

Таблица 1. Некоторые сведения об эффективности и безопасности вандетаниба и кабозантиниба, полученные в рамках ключевых многонациональных клинических исследований III фазы с участием пациентов с распространенным медуллярным раком шитовидной железы [7, 8]*

\section{Показатель}

Медиана выживаемости без прогрессирования (по сравнению с таковой в группе плацебо), мес

$\mathrm{P}$

Частота объективного ответа (все случаи частичного ответа в соответствии с критериями RECIST), \% ОШ (95\% ДИ) $\mathrm{P}$

Частота достижения контроля над заболеванием, \% ОШ (95\% ДИ) $\mathrm{P}$

Биохимический ответ

Уровень кальцитонина

$\mathrm{P}$

Биохимический ответ

Уровень раково-эмбрионального антигена $\mathrm{P}$

Токсические побочные эффекты (любой степени тяжести) как минимум у $30 \%$ пациентов

Частота прерывания терапии препаратом из-за развития побочных эффектов, \%

Частота снижения дозы из-за развития побочных эффектов, \%
ОР (95\% ДИ)

\begin{tabular}{|c|c|}
\hline $\begin{array}{c}\text { Вандетаниб - } \\
\text { исследование ZETA }\end{array}$ & $\begin{array}{c}\text { Кабозантиниб - } \\
\text { исследование ЕХАМ }\end{array}$ \\
\hline Не достигнута $(19,3)$ ** & $11,2 \operatorname{мес~}(4,0) * *$ \\
\hline $\begin{array}{c}0,46(0,31-0,69) \\
<0,001\end{array}$ & $\begin{array}{c}0,28(0,19-0,40) \\
\quad<0,001\end{array}$ \\
\hline 45 & 28 \\
\hline $\begin{array}{c}5,48(2,99-10,79) \\
<0,001\end{array}$ & $\begin{array}{c}\text { (ОШ не представлено) } \\
<0,001\end{array}$ \\
\hline $\begin{array}{c}87 \\
2,64(1,48-4,69) \\
0,001\end{array}$ & $\begin{array}{c}94 \\
\text { (ОШ не представлено) }\end{array}$ \\
\hline $\begin{array}{c}69 \% \text { пациентов } \\
\text { ОШ, } 72,9(26,2-303,2) \\
<0,001\end{array}$ & $\begin{array}{c}-45 \%, \text { среднее } \\
+57 \% \text { (среднее, } \\
\text { в сравнении с плацебо }) \\
<0,001\end{array}$ \\
\hline $\begin{array}{c}52 \% \text { пациентов } \\
\text { ОШ, 52,0 }(16,0-320,3) \\
<0,001\end{array}$ & $\begin{array}{c}-24 \%, \text { среднее } \\
+89 \% \text { (среднее, плацебо) } \\
<0,001\end{array}$ \\
\hline $\begin{array}{c}\text { Диарея, сыпь, тошнота, } \\
\text { артериальная гипертен- } \\
\text { зия }\end{array}$ & $\begin{array}{c}\text { Диарея, ладонно- } \\
\text { подошвенная } \\
\text { эритродизестезия, } \\
\text { снижение аппетита, } \\
\text { снижение массы тела, } \\
\text { тошнота, утомляемость }\end{array}$ \\
\hline 12 & 16 \\
\hline 35 & 79 \\
\hline
\end{tabular}

*Непосредственное сравнение результатов невозможно из-за различий выборок пациентов и дизайна исследований.

** В скобках указано значение в группе плацебо.

Примечание. ДИ - доверительный интервал; ОР - отношение рисков; ОШ - отношение шансов; ЕХАМ - исследование по оценке эффективности кабозантиниба для лечения распространенного медуллярного рака щитовидной железы (Еfficасу of XL184 (Cabozantinib) in Advanced Medullary Thyroid Cancer); RECIST - критерии оценки ответа солидных опухолей (Response Evaluation Criteria in Solid Tumors); ZETA - исследование по оценке эффективности вандетаниба для лечения рака щитовидной железы (Zactima Efficacy in Thyroid Cancer Assessment). 
$[8,9]$. К примеру, различия в выживаемости без прогрессирования (ВБП) в этих исследованиях (особенно заметные в группах плацебо) отражают ключевые различия в принципах отбора пациентов (критерии включения/исключения): в исследование ЕХАМ, оценивавшее эффективность кабозантиниба, набирались только больные с рентгенографически подтвержденным прогрессированием заболевания на момент включения, что обусловило меньшее количество участников и низкую ВБП в группе плацебо (всего 4 мес), в то время как для участия в исследовании ZETA, направленном на определение эффективности вандетаниба, рентгенографического подтверждения прогрессирования не требовалось, вследствие чего ВБП в группе плацебо была более высокой $(19,3$ мес) $[8,9]$. Кроме того, в исследовании вандетаниба был разрешен переход пациентов из группы плацебо в группу препарата, что усложнило оценку общей выживаемости. В исследовании кабозантиниба «перекрестная модель» не использовалась, что потенциально повысило надежность оценки влияния препарата на общую выживаемость $[8,9]$.

\section{Основа токсичностu мультикиназных ингибиторов}

Вандетаниб и кабозантиниб относятся к ИПК широкого спектра, и круг их мишеней в значительной степени совпадает [6, 7]. Эти препараты действуют в первую очередь на рецепторы к фактору роста эндотелия сосудов (vascular endothelial growth factor receptors, VEGFR), а также на многие тирозинкиназы, вовлеченные в патогенез МРЩЖ, в том числе мутантный RET $[6,7]$. Эффективность и токсичность различных ИПК достаточно близки и, вероятно, отражают характерную для каждого препарата аффинность. K мишеням вандетаниба относят VEGFR, RET, семейство рецепторов к эпидермальным факторам роста (epidermal growth factor receptor, EGFR), TIE2, семейство Ерh-рецепторов и семейство не связанных с клеточным рецептором Src-киназ [6]. В доклинических исследованиях вандетаниб ингибировал процессы ангиогенеза в опухоли, снижал проницаемость сосудов и останавливал рост опухоли и метастазирование [6].

Кабозантиниб также обладает активностью в отношении некоторых из этих мишеней, в том числе белков семейства VEGFR, RET, TIE2, а также действует на MET, KIT, TRKB, FLT3, AXL, TYRO3 и ROS1 [7]. Доклинические исследования кабозантиниба продемонстрировали его способность угнетать ангиогенез в опухоли, нарушать ее васкуляризацию, ограничивать миграцию, инвазию и пролиферацию опухолевых клеток, а также вызывать гибель опухолевых клеток [7, 10].

\section{Tepanuя расnространенного медуллярного рака} щитовидной железы: кого мы лечим и почему

Отбор пациентов с распространенным МРЩЖ для лечения ИПК должен проводиться очень осторожно. В исследовании вандетаниба III фазы участвовали взрослые пациенты с нерезектабельным, местно-распространенным или метастатическим МРЩЖ (наследственным или спорадическим), у которых диагноз был подтвержден при биопсии или при обнаружении герминативных мутаций $R E T$; прогрессирование опухоли не учитывалось. Одним из критериев включения в исследование был уровень кальцитонина в сыворотке крови $\geq 500$ пг/мл. Пациенты с выраженными нарушениями работы сердца, печени, почек, а также кроветворения исключались. К участию допускались пациенты, ранее прошедшие лечение по поводу МРЩЖ (включая химиотерапию или терапию другими ИПК) [9]. Отбор участников для исследования кабозантиниба III фазы был во многом схожим: включались взрослые пациенты с гистологически подтвержденным нерезектабельным, местно-распространенным или метастатическим МРЩЖ. Однако в отличие от исследования вандетаниба для включения в исследование кабозантиниба не требовалось рентгенографическое подтверждение прогрессирования опухоли в течение предшествовавших $14 \mathrm{мес} \mathrm{[8].}$

ИПК условно рекомендованы к применению клиническими руководствами по лечению онкологических заболеваний Общенациональной онкологической сети США (NCCN clinical practice guidelines in oncology) (уровень достоверности доказательств и согласованности рекомендаций 1) и клиническим руководством Американской ассоциации специалистов по лечению заболеваний щитовидной железы (American Thyroid Association) (уровень достоверности доказательств и согласованности рекомендаций А). В данных руководствах указано, что лечение необходимо только при симптомном или прогрессирующем течении заболевания, а повышение уровня опухолевых маркеров само по себе не является достаточным основанием для начала терапии $[1,2]$. Активное наблюдение рекомендуется, как правило, при стабилизации заболевания, его медленном прогрессировании или индолентном течении, при котором либо симптомы отсутствуют, либо есть некоторая вероятность их возникновения [1]. Поэтому необходимо оценить соотношение риска и пользы в каждом конкретном случае МРЩЖ, чтобы определить, следует ли начинать терапию ИПК и в какой момент [1, 2, 6].

К особенностям пациента, которые следует учитывать при назначении лечения, относятся тяжесть онкологического заболевания, локализация опухоли и темпы прогрессирования, возраст пациента, наличие сопутствующих заболеваний (например, уже имеющееся удлинение интервала QT или печеночная недостаточность) и, что немаловажно, предпочтения самого пациента. Поскольку на сегодняшний день очередность применения различных ИПК не регламентирована в рекомендациях, то выбор препарата 
Таблица 2. Некоторые фармакокинетические свойства вандетаниба и кабозантиниба и их взаимодействие с другими лекарственными средствами $[5,6]$ *

\begin{tabular}{|c|c|c|}
\hline Показатель & Вандетаниб & Кабозантиниб \\
\hline \multicolumn{3}{|c|}{ Фармакокинетика } \\
\hline $\begin{array}{l}\text { Время достижения максимальной концентрации } \\
\text { в плазме крови }\end{array}$ & Медиана 6 ч (диапазон 4-10 ч) & Диапазон 2-5 ч \\
\hline $\begin{array}{l}\text { Время достижения стабильной концентрации } \\
\text { в плазме крови }\end{array}$ & Через 3 мес & Через 15 дней \\
\hline Период полувыведения препарата из плазмы крови & 19 дней & 55 ч \\
\hline $\begin{array}{l}\text { Влияние пищи (с высоким содержанием жира) } \\
\text { на скорость усвоения }\end{array}$ & Нет данных & $\begin{array}{l}\text { Cmax увеличивается на } 41 \% \\
\text { AUC увеличивается на } 57 \%\end{array}$ \\
\hline Путь выведения & $\begin{array}{l}44 \% \text { с фекалиями } \\
25 \% \text { с мочой }\end{array}$ & $\begin{array}{l}54 \% \text { с фекалиями } \\
27 \% \text { с мочой }\end{array}$ \\
\hline \multicolumn{3}{|c|}{ Выведение } \\
\hline Умеренная почечная недостаточность & AUC увеличивается на $39 \%$ & Не влияет \\
\hline Тяжелая почечная недостаточность & AUC увеличивается на $41 \%$ & Неизвестно \\
\hline Легкая печеночная недостаточность & Не влияет & AUC увеличивается на $81 \%$ \\
\hline Умеренная печеночная недостаточность & $\begin{array}{l}\text { Применение не рекомендовано } \\
\text { (также при тяжелой печеноч- } \\
\text { ной недостаточности) }\end{array}$ & AUC увеличивается на $63 \%$ \\
\hline Метаболизм & При участии СУР3А4 & При участии СУР3А4 \\
\hline \multicolumn{3}{|c|}{ Взаимодействие с другими лекарственными препаратами } \\
\hline Сильные индукторы СУР3А4 & AUC снижается на $40 \%$ & AUC снижается на $77 \%$ \\
\hline Сильные ингибиторы СУР3А4 & Не влияет & AUC увеличивается на 38 \% \\
\hline Другие субстраты СYР450 & $\begin{array}{l}\text { Не влияет на AUC мидазолама } \\
\text { (субстрата CYP3A4) }\end{array}$ & $\begin{array}{l}\text { Не влияет на AUC розиглита- } \\
\text { зона (субстрата CYP2C8) }\end{array}$ \\
\hline Субстраты гликопротеина P & $\begin{array}{l}\text { AUC дигоксина увеличивается } \\
\text { на } 23 \%\end{array}$ & $\begin{array}{l}\text { Возможно увеличение экспо- } \\
\text { зиции для других субстратов }\end{array}$ \\
\hline Другие транспортеры & $\begin{array}{l}\text { AUC метформина (субстрата } \\
\text { OCT2) увеличивается на } 74 \%\end{array}$ & $\begin{array}{l}\text { Возможно увеличенияе } \\
\text { экспозиции для кабозантиниба } \\
\text { и ингибиторов MRP2 }\end{array}$ \\
\hline $\begin{array}{l}\text { рН желудочного сока (необходимость применения } \\
\text { ингибиторов протонной помпы или блокаторов } \\
\text { H }_{2} \text {-гистаминовых рецепторов) }\end{array}$ & Не влияет & Не влияет \\
\hline \multicolumn{3}{|c|}{ 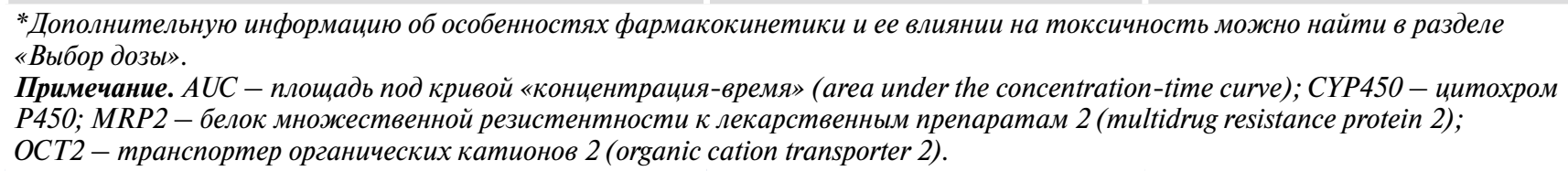 } \\
\hline
\end{tabular}

(вандетаниба или кабозантиниба) осуществляется в индивидуальном порядке [1, 2]. В действительности в течение жизни большинство пациентов получат оба эти препарата по отдельности, поэтому выбор в пользу того или другого для терапии 1-й линии в данном случае зависит от предпочтений врача и особенностей пациента. В клинической практике у многих пациентов, вероятно, в анамнезе будут сопутствующие заболевания (которых не было у пациентов, принявших участие в клинических испытаниях), что также должно учитываться. Лечение некоторых пациентов может оказаться куда более сложным из-за токсических побочных эффектов. Определенные фармакокинетические свойства вандетаниба и кабозантиниба и особенности их взаимодействия с другими лекарственными средствами будут важны как для выбора стартовой терапии, так и для преодоления побочных эффектов (табл. 2) [6, 7]. 


\section{Выбор дозы}

Лечение вандетанибом и/или кабозантинибом, как правило, длительное, поэтому у многих пациентов развиваются побочные эффекты [8, 9]. Очевидно, врач должен четко знать методы преодоления побочных эффектов, а также обладать достаточным опытом, чтобы вовремя распознать развитие токсичных эффектов и назначить адекватное лечение. Раннее выявление побочных эффектов и подбор оптимальных средств для их коррекции необходимы для обеспечения хорошей переносимости препаратов и высокой приверженности пациентов к лечению. Уменьшение рисков способствует улучшению исходов лечения и поддерживает качество жизни пациентов на приемлемом уровне [11]. Лечение побочных эффектов предполагает в первую очередь облегчение симптомов с помощью различных препаратов, доступных по рецепту и без него (например, лечение артериальной гипертензии, снижение дерматологической токсичности, своевременная коррекция дозы левотироксина) $[9,11]$. Если эти меры неэффективны, прием препарата прерывают на какое-то время [11]. В последнюю очередь как способ коррекции побочных эффектов рассматривают уменьшение дозы. При этом применение максимально допустимой для пациента и, следовательно, эффективной дозы препарата стараются продлить на максимальный срок.

Вандетаниб. Рекомендованная стартовая доза вандетаниба - 300 мг/сут, она может быть снижена до 200 мг/сут только при клиренсе креатинина $<50$ мл/мин. Стартовая доза также может быть снижена при легкой печеночной недостаточности; назначение же вандетаниба пациентам с умеренной или тяжелой печеночной недостаточностью (при уровне билирубина в сыворотке крови, превышаюшем в 1,5 и более раза верхнюю границу нормы) не рекомендуется [6]. Стартовая доза может быть увеличена при одновременном назначении сильных индукторов CYР3А4, а при одновременном использовании сильных ингибиторов СYР3А4 доза должны быть снижена (в этом случае пациенты также должны избегать употребления грейпфрутового сока). Однако на практике такой подбор дозы может быть затруднен [6].

В процессе лечения дозы ИПК могут быть при необходимости снижены (для преодоления токсических эффектов) вплоть до минимальных, при которых все еще достигается терапевтический эффект. Доза вандетаниба может быть снижена с 300 до 200 мг/сут, а затем и до 100 мг/сут в том случае, если побочные эффекты III-IV степени тяжести не могут быть оперативно устранены другими способами [6]. Более низкие дозы могут быть достаточными для контроля заболевания. Так, в исследовании вандетаниба I фазы была показана возможность стабилизации заболевания при использовании доз 100 и 200 мг/сут [12]. Кроме того, коррекция дозы была частью стратегии в исследовании III фазы (ZETA) [9]. В одном из недавно завершенных испытаний IV фазы оценивалась эффективность вандетаниба в дозировке 150 мг/сут [13].

В случае возникновения тяжелых побочных эффектов лечение должно быть прервано. В инструкции особо выделена необходимость временной отмены вандетаниба при интервале QT >500 мс. Лечение может быть продолжено лишь при достижении целевых значений интервала QT (<450 мс), при этом необходимо снизить дозу [6]. Важно отметить, что удлинение интервала QT, требующее временной отмены препарата, характерно не только для вандетаниба, но и для всех ИПК. Лечение вандетанибом также прерывают при наличии у пациента других побочных эффектов III-IV степени тяжести. Возобновление лечения возможно после улучшения состояния пациента (снижения тяжести до І степени) при использовании сниженной дозы [6]. Следует учитывать фармакокинетические свойства вандетаниба при принятии решения о его временной отмене (см. табл. 2). Поскольку одно только снижение дозы вандетаниба не способно быстро устранить побочные эффекты в силу медленного выведения препарата из организма (период полувыведения 19 дней), решение о временной отмене должно приниматься быстро, чтобы по возможности предотвратить тяжелые токсические эффекты [6].

Кабозантиниб. В соответствии с инструкцией рекомендованная стартовая доза кабозантиниба - 140 мг/сут. Пациентам с легкой и умеренной печеночной недостаточностью (класса А или В по классификации ЧайлдаПью) рекомендована стартовая доза 80 мг/сут [7]. В табл. 2 описаны заболевания печени, при которых требуется снижение дозы [7]. Многие опытные специалисты по лечению МРЩЖ предпочитают изначально назначать 80 или даже 60 мг/сут из-за частых и весьма тяжелых токсических эффектов, наблюдаемых при использовании более высоких доз [14]. В случае необходимости нивелирования токсических эффектов доза кабозантиниба может быть снижена со 140 до 100 мг/сут, а затем до 80 или 60 мг/сут [7]. С другой стороны, при хорошей переносимости препарата в стартовой дозе 60 или 80 мг/сут доза может быть в последующем увеличена. Сейчас в рамках одного из клинических испытаний IV фазы проводится изучение эффективности кабозантиниба в дозе 60 мг/сут [15]. При одновременном назначении кабозантиниба с сильными ингибиторами СУРЗА4 его дозировку уменьшают до 40 мг/сут [7]; многим пациентам требуется дальнейшее снижение дозы до 20 мг/сут. Лечение прерывают при наличии у пациента токсических эффектов III степени тяжести, гематологических побочных эффектов IV степени тяжести, любых побочных эффектов II степени тяжести при их плохой переносимости [7], но только в том случае, если 
их не удается устранить другими способами. Терапию возобновляют после улучшения состояния (снижении тяжести эффектов до I степени), но применяют меньшие дозы препарата [7].

Общие рекомендации. Лечение ИПК должно быть персонализированным. Следует использовать 2 способа преодоления токсичности: 1) дополнительную паллиативную терапию для своевременного лечения возникающих токсических эффектов, 2) временную отмену препарата или снижение дозы, если это необходимо. Однако следует приложить максимальные усилия для повышения переносимости лечения и поддержания максимально возможной для конкретного пациента дозы препарата. Побочные эффекты лечения ИПК могут быть весьма тяжелыми и даже опасными для жизни, поэтому врач должен обладать достаточным опытом и ресурсами для быстрого решения возникающих проблем.

Поскольку большинство специалистов, которые привлекаются к ведению пациентов с МРЩЖ, могут быть незнакомы с особенностями таких препаратов, как вандетаниб и кабозантиниб, полагаться на них в вопросе обеспечения оптимальной организации лечения было бы неразумно. Таким образом, в данном случае предпочтительно направлять лечение каждого пациента индивидуально, что может быть обеспечено несколькими способами. Пациенты, принимающие ИПК, могут быть сначала обеспечены учебными материалами о токсических эффектах, требующих медицинского вмешательства. В идеале пациенты должны иметь возможность быстро связаться со своим лечащим врачом, чтобы задать вопросы о возникающих побочных эффектах и получить необходимые рекомендации. Если это невозможно, следует рассмотреть возможность направления пациента в специализированный центр с более широкими возможностями.

Рекомендациu no лечению ассоциированных с лечением токсическuх эффектов

Побочные эффекты вандетаниба. Наиболее распространенными токсическими эффектами (любой степени тяжести), ассоциированными с приемом вандетаниба, являются диарея, сыпь, тошнота, артериальная гипертензия, головная боль, повышенная утомляемость, снижение аппетита, акне, сухость кожи, акнеподобный дерматит, астения, рвота и удлинение интервала QT. K самым серьезным нежелательным явлениям (III-IV степени тяжести) относят диарею, артериальную гипертензию, удлинение интервала QT, повышенную утомляемость, снижение аппетита, сыпь и астению (табл. 3) [8, 9].

Побочные эффекты кабозантиниба. Кабозантиниб и вандетаниб имеют сходный спектр токсических эффектов. Кабозантиниб тоже может вызывать у пациентов диарею, снижение аппетита, тошноту, повышен- ную утомляемость и артериальную гипертензию. Однако прием кабозантиниба часто ассоциирован с уникальными токсическими эффектами, такими как ладонно-подошвенная эритродизестезия/ладонноподошвенный синдром (ЛПЭ/ЛПС), дисгевзия и стоматит. Кроме того, кабозантиниб характеризуется широким спектром серьезных эффектов (III-IV степени тяжести), в числе которых диарея, ЛПЭ/ЛПС, повышенная утомляемость, артериальная гипертензия, астения, снижение массы тела, снижение аппетита, дисфагия, кровотечения и воспаление слизистых оболочек (см. табл. 3) [8].

Удлинение интервала QT при приеме вандетаниба. При назначении вандетаниба следует учитывать такой важный его эффект, как непосредственное ингибирование не связанных с клеточным рецептором киназ, что проявляется дозозависимым удлинением интервала QT. В основе этого потенциально тяжелого осложнения лежит взаимодействие препарата с калиевыми ионными каналами клеток миокарда, задействованными в реполяризации сердечной мышцы $[6,16]$. В исследовании вандетаниба III фазы удлинение интервала QT наблюдалось у 14 \% пациентов, причем у 8 \% были зафиксированы серьезные нарушения (III и IV степени тяжести) [9]. В исследовании кабозантиниба III фазы, напротив, ни у одного из участников не было зафиксировано удлинение интервала QT (>500 мс) [8]. Ранее было показано, что прием вандетаниба может приводить к развитию пируэтной тахикардии, желудочковой тахикардии и даже внезапной смерти [6]. Однако в рамках клинического испытания вандетаниба III фазы подобных побочных эффектов не наблюдалось, так же как и не было установлено четкой связи между внезапной смертью и удлинением интервала QT [9]. Вандетаниб противопоказан пациентам с врожденным синдромом удлинения интервала QT, длительностью интервала QT >450 мс до начала терапии (в странах Евросоюза >480 мс), пируэтной тахикардией, брадиаритмией или декомпенсированной сердечной недостаточностью в анамнезе, а также пациентам с гипокальциемией, гипокалиемией или гипомагниемией. Следует иметь в виду, что период полувыведения вандетаниба составляет 19 дней, следовательно, восстановление интервала QT может потребовать времени [6].

Перед началом лечения все пациенты должны проходить обязательное обследование, включающее электрокардиографию, а также лабораторное определение уровня калия, кальция, магния и тиреотропного гормона (ТТГ) в сыворотке крови. Повторные обследования проводят через 2-4 и 8-12 нед, далее - каждые 3 мес (у пациентов с диареей чаще). Кроме того, все вышеописанные диагностические процедуры следует повторить, если пациенту потребовалось снижение дозы препарата или его отмена на период более 2 нед. Перед началом лечения необходимо провести 
Таблица 3. Наиболее распространенные побочные эффекты вандетаниба и кабозантиниба (в том числе серьезные), возникшие у участников исследований III фазы [7, 8] *

\section{Вандетаниб}

Кабозантиниб

Наиболее распространенные побочные эффекты (любой степени тяжести), наблюдавшиеся не менее чем у 10 \% пациентов

\begin{tabular}{|c|c|c|c|}
\hline Побочный эффект & $\%$ & Побочный эффект & $\%$ \\
\hline Диарея & 56 & Диарея & 63 \\
\hline Сыпь & 45 & ЛПЭ & 50 \\
\hline Тошнота & 33 & Снижение массы тела & 48 \\
\hline Артериальная гипертензия & 32 & Снижение аппетита & 46 \\
\hline Головная боль & 26 & Тошнота & 43 \\
\hline Утомляемость & 24 & Утомляемость & 41 \\
\hline Снижение аппетита & 21 & Дисгевзия & 34 \\
\hline Акне & 20 & Изменение цвета волос & 34 \\
\hline Сухость кожи & 15 & Артериальная гипертензия & 33 \\
\hline Акнеподобный дерматит & 15 & Стоматит & 33 \\
\hline Астения & 14 & Запоры & 29 \\
\hline Рвота & 14 & Кровотечение & 25 \\
\hline Удлинение интервала QT & 14 & Рвота & 24 \\
\hline Боль в животе & 14 & Воспаление слизистой оболочки & 23 \\
\hline Бессонница & 13 & Астения & 21 \\
\hline Назофарингит & 11 & Сыпь & 19 \\
\hline Кашель & 10 & Орофарингеальная боль & 18 \\
\hline Снижение массы тела & 19 & Диспепсия & 11 \\
\hline
\end{tabular}

Серьезные нежелательные явления (III-IV степени тяжести), наблюдавшиеся не менее чем у 3 \% пациентов

\begin{tabular}{|l|l|l|l|}
\hline Диарея & 11 & Диарея & 16 \\
\hline Артериальная гипертензия & 9 & Ладонно-подошвенная эритродизестезия & 13 \\
\hline Удлинение интервала QТ & 8 & Утомляемость & 9 \\
\hline Утомляемость & 6 & Артериальная гипертензия & 8 \\
\hline Снижение аппетита & 4 & Астения & 6 \\
\hline Сыпь & 4 & Снижение массы тела & 5 \\
\hline Астения & 3 & Снижение аппетита & 5 \\
\hline & & Дисфагия & 4 \\
\hline
\end{tabular}

*Дополнительную информацию о конкретных побочных эффектах, представленных в данной таблице, можно найти в разделе «Нежелательные явления».

коррекцию гипокальциемии, гипокалиемии и гипомагниемии в случае их выявления у пациента.
Вандетаниб не следует назначать одновременно с препаратами, способствующими удлинению интервала QT 
Таблица 4. Клинический алгоритм для пациентов, получающих вандетаниб [5, 16]

\begin{tabular}{|c|c|c|c|c|c|c|c|c|c|}
\hline Процедура & 产 & 突 & 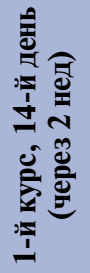 & 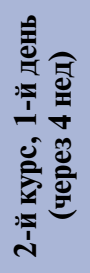 & 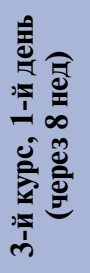 & 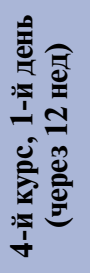 & 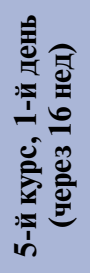 & 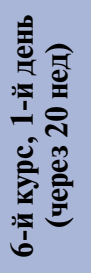 & 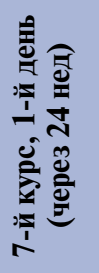 \\
\hline $\begin{array}{l}\text { Подтверждение диагноза } \\
\text { медуллярного рака щитовидной }_{\text {железы }^{1}}\end{array}$ & $\mathrm{X}$ & & & & & & & & \\
\hline $\begin{array}{l}\text { Электрокардиография; интервал } \\
\text { QT должен быть } \leq 450 \text { мс }^{2}\end{array}$ & $\mathrm{X}$ & & $X$ & & $X$ & & & $X$ & \\
\hline $\begin{array}{l}\text { Сердечно-сосудистые заболевания } \\
\text { в анамнезе }\end{array}$ & $\mathrm{X}$ & & & & & & & & \\
\hline $\begin{array}{l}\text { Лабораторные исследования: } \\
\text { определение уровня магния, } \\
\text { кальция, калия и тиреотропного } \\
\text { гормона }{ }^{4}\end{array}$ & $\mathrm{X}$ & & $X$ & & X & & & $X$ & \\
\hline Анализ проводимого лечения 5 & $\mathrm{X}$ & & $\mathrm{X}$ & $X$ & $X$ & $\mathrm{X}$ & $X$ & $X$ & $X$ \\
\hline $\begin{array}{l}\text { Рентгенологическое обследования } \\
\text { для выяснения стадии заболевания }\end{array}$ & $\mathrm{X}$ & & & & $\mathrm{X}$ & & $X$ & & $\mathrm{X}$ \\
\hline Прием врача & $\mathrm{X}$ & & $\mathrm{X}$ & $\mathrm{X}$ & $\mathrm{X}$ & $\mathrm{X}$ & $\mathrm{X}$ & $X$ & $\mathrm{X}$ \\
\hline \multicolumn{10}{|c|}{$\begin{array}{l}{ }^{1} \text { Вандетаниб - ингибитор протеинкиназ, предназначенный для лечения симптомного, прогрессирующего, нерезектабельного } \\
\text { местно-распространенного или метастазирующего медуллярного рака щитовидной железы. } \\
{ }^{2} \text { Вандетаниб противопоказан пациентам с интервалом } Q T>450 \text { мс. } \\
{ }^{3} \text { Вандетаниб противопоказан пациентам с врожденным синдромом удлинения интервала QT, а также больным с пируэтной } \\
\text { тахикардией, брадиаритмией или декомпенсированной сердечной недостаточностью в анамнезе. } \\
{ }^{4} \text { Для снижения риска удлинения интервала QТ нужно следить, итобы концентрация калия в сыворотке сохранялась на уровне } \\
\geq 4 \text { мэкв/л (в рамках нормы); концентрации магния и кальия в сыворотке также должны поддерживаться в пределах нормы. } \\
{ }_{5}^{5} \text { Вандетаниб не следует принимать одновременно с другими лекарственными средствами, способными удлинять инттервал } \\
\text { QТ, а также с препаратами, вызывающими пируэтную тахикардию. Сюда относятся антиаритмические средства (в том } \\
\text { числе амиодарон, дизопирамид, прокаинамид, соталол, дофетилид и др.) и другие препараты (в том числе хлорохин, клари- } \\
\text { тромицин, доласетрон, гранисетрон, галоперидол, метадон, моксифлоксацин, пимозид и др.). }\end{array}$} \\
\hline
\end{tabular}

(например, амиодароном, хлорохином, кларитромицином, гранисетроном, метадоном и др.). Клинический алгоритм ведения пациентов, получающих вандетаниб, представлен в табл. 4 [6].

В силу высокого риска развития серьезных осложнений всем врачам-онкологам рекомендуется пройти сертификацию в рамках программы CAPRELSA Risk Evaluation and Mitigation Strategy (REMS) перед тем, как назначать данный препарат пациентам [6, 17]. Подобное ограниченное распространение и необходимость обучения врачей в рамках REMS могут выглядеть как дополнительные препятствия, однако эта информация абсолютно необходима для оптимизации назначения терапии: как удлинение интервала QT, так и распространенный МРЩЖ являются опасными для жизни состояниями, поэтому возможные риски и польза от назначения вандетаниба должны быть тщательно взвешены. Кроме того, по нашему опыту, удлинение интервала QT следует скорее относить к так называемым классовым эффектам, т. е. таким, которые проявляются в разной степени при приеме любых препаратов класса ингибиторов VEGFR.

\section{Apmepuaльная гunepmeнзия и кардиоваскулярная токсичность}

Специалисты, занимающиеся лечением распространенных форм МРЩЖ, должны помнить, что высокая частота сердечно-сосудистых заболеваний в общей популяции, вероятнее всего, будет наблюдаться и среди их пациентов [18]. Установлено, что прием ингибиторов VEGF ассоциирован с рядом побочных эффектов со стороны сердечно-сосудистой системы, включая артериальную гипертензию и повреждение сосудов.

Вандетаниб. В рамках клинических испытаний вандетаниба и кабозантиниба зафиксирована пример- 
но одинаковая распространенность артериальной гипертензии [8, 9]. Артериальная гипертензия разной степени тяжести наблюдалась у $23 \%$ пациентов, принимавших вандетаниб, при этом 9 \% пациентов страдали от тяжелой артериальной гипертензии (IIIIV степени тяжести) [9].

Кабозантиниб. В клиническом испытании кабозантиниба $33 \%$ участников страдали артериальной гипертензией разной степени тяжести, а у $8 \%$ пациентов наблюдалась тяжелая артериальная гипертензия (IIIIV степени тяжести) [8]. В аннотации к препарату сказано, что у 96 \% пациентов артериальное давление (АД) повышается незначительно (предгипертония, или артериальная гипертензия, при которой систолическое АД $\geq 120$ мм рт. ст. или диастолическое АД $\geq 80$ мм рт. ст.), однако ни у одного из пациентов не развилась злокачественная артериальная гипертензия [7].

Лечение. Лечение вандетанибом или кабозантинибом не следует начинать до тех пор, пока систолическое АД пациента не будет $<150$ мм рт. ст. При дальнейшем мониторинге АД нужно иметь в виду, что артериальная гипертензия может развиться в течение недели после начала лечения [18]. Обязателен регулярный контроль АД в ходе лечения, а также продолжение медикаментозной терапии у пациентов с уже имеющейся артериальной гипертензией. Амлодипин и другие блокаторы кальциевых каналов являются в данной ситуации наиболее безопасными и эффективными препаратами для лечения артериальной гипертензии. При отсутствии терапевтического эффекта следует рассмотреть возможность назначения ингибиторов ангиотензинпревращающего фермента, блокаторов рецепторов к ангиотензину II или диуретиков в качестве дополнения к основному лечению. Фармакотерапия должна быть назначена оперативно с целью поддержания систолического АД на уровне <150 мм рт. ст.; по нашему опыту, это почти всегда возможно. Тем не менее в редких случаях может потребоваться временная или даже полная отмена лечения вследствие тяжелой или трудно поддающейся лечению артериальной гипертензии (чаще всего у пациентов с имевшейся в анамнезе артериальной гипертензией), чтобы избежать серьезных неврологических или кардиологических осложнений, таких как кардиомиопатия [6, 7, 16]. В данном случае мы рекомендуем регулярное (раз в год) проведение эхокардиографии у пациентов, принимающих ингибиторы VEGFR в течение года и долее.

\section{Диарея и другие побочные эффекты со стороны желудочно-кишечного тракта}

Диарея относится к достаточно распространенным побочным эффектам ИПК, в том числе вандетаниба и кабозантиниба. Причиной ее развития является, по всей видимости, ингибирование VEGFR и EGFR, которые экспрессируются в клетках слизистой оболочки желудочно-кишечного тракта (ЖКТ) [19, 20]. Кроме того, диарея часто наблюдается у пациентов с распространенным МРЩЖ и метастазами в печень вследствие гиперсекреции кальцитонина и других продуцируемых опухолевыми клетками гормонов, что в итоге усиливает моторику ЖКТ [2]. Поскольку диарея - ключевой симптом МРШЖ, назначение ИПК может значительно усугубить ее тяжесть. Хотя лечение основного заболевания ИПК и снижение уровня кальцитонина иногда способны уменьшить выраженность диареи, это происходит далеко не всегда. К другим частым побочным эффектам вандетаниба со стороны органов ЖКТ относятся тошнота, диспепсия, боль в животе и снижение аппетита (см. табл. 3) [6-9].

Вандетаниб. Диарея - наиболее распространенный побочный эффект вандетаниба, зафиксированный в рамках клинического испытания этого препарата (см. табл. 3): 56 \% пациентов предъявляли жалобы на диарею разной степени тяжести, в основном I или II степени. Тяжелая диарея (III-IV степени тяжести) зарегистрирована в $11 \%$ случаев. Организаторы исследования утверждают, что в большинстве случаев диарея поддавалась поддерживающей терапии [9].

Кабозантиниб. В клиническом испытании кабозантиниба диарея различной степени тяжести наблюдалась у 63 \% участников; тяжелая диарея (III-IV степени тяжести) зафиксирована в $16 \%$ случаев (см. табл. 3). Пациентам с диарей назначали поддерживающую терапию, а также снижали дозу препарата или временно его отменяли (в соответствии с обычными принципами лечения побочных эффектов) [8]. Перед началом терапии ИПК необходимо приложить все усилия для борьбы с МРЩЖ-ассоциированной диарей. Наиболее эффективны лоперамид и дифеноксилат/атропин. Пациенты должны быть проинформированы о возможности диареи и методах ее лечения, включающих ежедневный прием препаратов; не следует пассивно ожидать ее развития [11]. В случае неконтролируемой диареи небольшие дозы кодеина и опиума ежедневно могут облегчить симптомы и предотвратить снижение дозы кабозантиниба.

Лечение. Подробное описание терапевтических мероприятий, направленных на борьбу с диареей и диспепсией, представлено в табл. 5 [6, 7, 11, 17, 2023]. Если диарея развивается в ответ на лечение ИПК, то следует провести электрокардиографию и определить уровень электролитов в сыворотке крови. Это необходимо для выявления больных с удлинением интервала QT, которое может быть следствием обезвоживания и нехватки электролитов [6]. Пациенты должны быть предупреждены о необходимости информирования своего лечащего врача о развитии диареи, а также о том, что нужно вести учет регулярности стула при каждом визите к врачу. Врач должен оценить 
Таблица 5. Рекомендации по профилактике и лечению диареи и диспепсии, связанных с приемом ингибиторов протеинкиназ [5, 6, 10, 16, 19-22]*

\begin{tabular}{|c|c|}
\hline \multicolumn{2}{|r|}{ Диарея } \\
\hline $\begin{array}{l}\text { Общие рекомендации } \\
\text { при диарее I-II степени } \\
\text { тяжести }\end{array}$ & $\begin{array}{l}\text { - Пациент должен информировать врача о возникновении диареи I-II степени тяжести. } \\
\text { - Сначала следует рассмотреть диетические и медикаментозные методы (см. ниже). } \\
\text { • В большинстве случаев временной отмены препарата или снижения дозы не требуется. } \\
\text { - Своевременные профилактические меры помогут избежать развития хронической } \\
\text { диареи, которая может привести к обезвоживанию и нарушить баланс электролитов } \\
\text { в организме }\end{array}$ \\
\hline $\begin{array}{l}\text { Общие рекомендации } \\
\text { при диарее III-IV степени } \\
\text { тяжести }\end{array}$ & $\begin{array}{l}\text { • Временно приостановить лечение, чтобы подобрать оптимальные способы контроля } \\
\text { диареи. } \\
\text { • Возобновить лечение можно после уменьшения степени тяжести диареи (до I степени } \\
\text { или ІІ степени при хорошей переносимости) со снижением дозы. } \\
\text { • Снизить дозу после всесторонней оценки пищевых привычек и приверженности } \\
\text { к противодиарейному лечению }\end{array}$ \\
\hline Обучение пациентов & $\begin{array}{l}\text { • Врач должен информировать пациента о возможности возникновения диареи и методах } \\
\text { ее лечения, а также о способах диетической коррекции. } \\
\text { • Пациент должен обязательно сообщать лечащему врачу о любых изменениях } \\
\text { в функционировании ЖКТ }\end{array}$ \\
\hline Наблюдение пациентов & $\begin{array}{l}\text { • Необходимо тщательно контролировать водный и электролитный баланс. } \\
\text { • Нужно отслеживать возникновение (или любые изменения) болей в животе, рвоты } \\
\text { или запоров для оценки риска перфорации ЖКТ, особенно у пациентов с дивертикули- } \\
\text { том/дивертикулезом или колитом в анамнезе. } \\
\text { • В случае неожиданного усиления диареи пациента следует обследовать на наличие } \\
\text { Clostridium difficile или других инфекций }\end{array}$ \\
\hline Диета & $\begin{array}{l}\text { • Проводимое лечение может вызвать изменения вкусовых ощущений и пищевых } \\
\text { привычек. } \\
\text { • Рекомендуется избегать кофеина, молочных и жирных продуктов, так как они усугубля- } \\
\text { ют токсические эффекты. } \\
\text { • Рекомендуется избегать продуктов с высоким содержанием пищевых волокон. } \\
\text { • Пациенты должны вести дневник питания для выявления продуктов, негативно } \\
\text { влияющих на работу ЖКТ. } \\
\text { • Оптимальная гидратация является основой лечения диареи (в дополнение } \\
\text { к противодиарейным препаратам) }\end{array}$ \\
\hline Пищевые добавки & $\begin{array}{l}\text { • Необходимо обеспечить возмещение потерянного кальция путем приема } \\
\text { соответствующих пищевых добавок }\end{array}$ \\
\hline Лечение & $\begin{array}{l}\text { • В основном симптоматическое: } \\
-\quad \text { при первых симптомах диареи назначить противодиарейный препарат, } \\
\text { не дожидаясь результата изменения диеты; } \\
\text { - лоперамид (имодиум®) в дозе } 2-4 \text { мг с пищей или без нее, затем по } 2 \text { мг каждые } \\
4 \text { ч или после каждого жидкого стула. } \\
\text { • Подобрать подходящую суточную дозу лоперамида и разбить на } 12 \text { приемов } \\
\text { при усугублении диареи. } \\
\text { Примечание: приведенное максимальное количество таблеток в день } \\
\text { не соответствует указаниям в инструкции к препарату. Следует проинформировать } \\
\text { пациента о максимально допустимых дозах и важности их соблюдения. } \\
\text { • Лоперамид в дозе } 2 \text { мг с профилактической целью за } 30 \text { мин до запланированного } \\
\text { приема ИПК - для пациентов, у которых предыдущие приемы препарата вызвали диарею. } \\
\text { • Дифеноксилат/атропин (ломотил®) с аналогичным повышением дозы, если лоперамид } \\
\text { неэффективен. }\end{array}$ \\
\hline Другие препараты & $\begin{array}{l}\text { • Можно дополнительно назначить настойку опиума или другие опиаты (например, } \\
\text { кодеин) для облегчения тяжелой диареи. } \\
\text { • Секвестранты желчных кислот способны облегчить симптомы ИПК-ассоциированной } \\
\text { диареи. } \\
\text { • Некоторым пациентам может помочь холестирамин. } \\
\quad \text { Примечание: стартовая доза должна составлять } 4 \text { г/сут с последующим } \\
\quad \text { увеличением до } 4 \text { г } 3 \text { раза в день. } \\
\text { Препарат принимают не позднее чем за } 4 \text { ч до приема тиреоидного гормона } \\
\quad \text { или через } 4 \text { ч после него }\end{array}$ \\
\hline
\end{tabular}


Окончание табл. 5

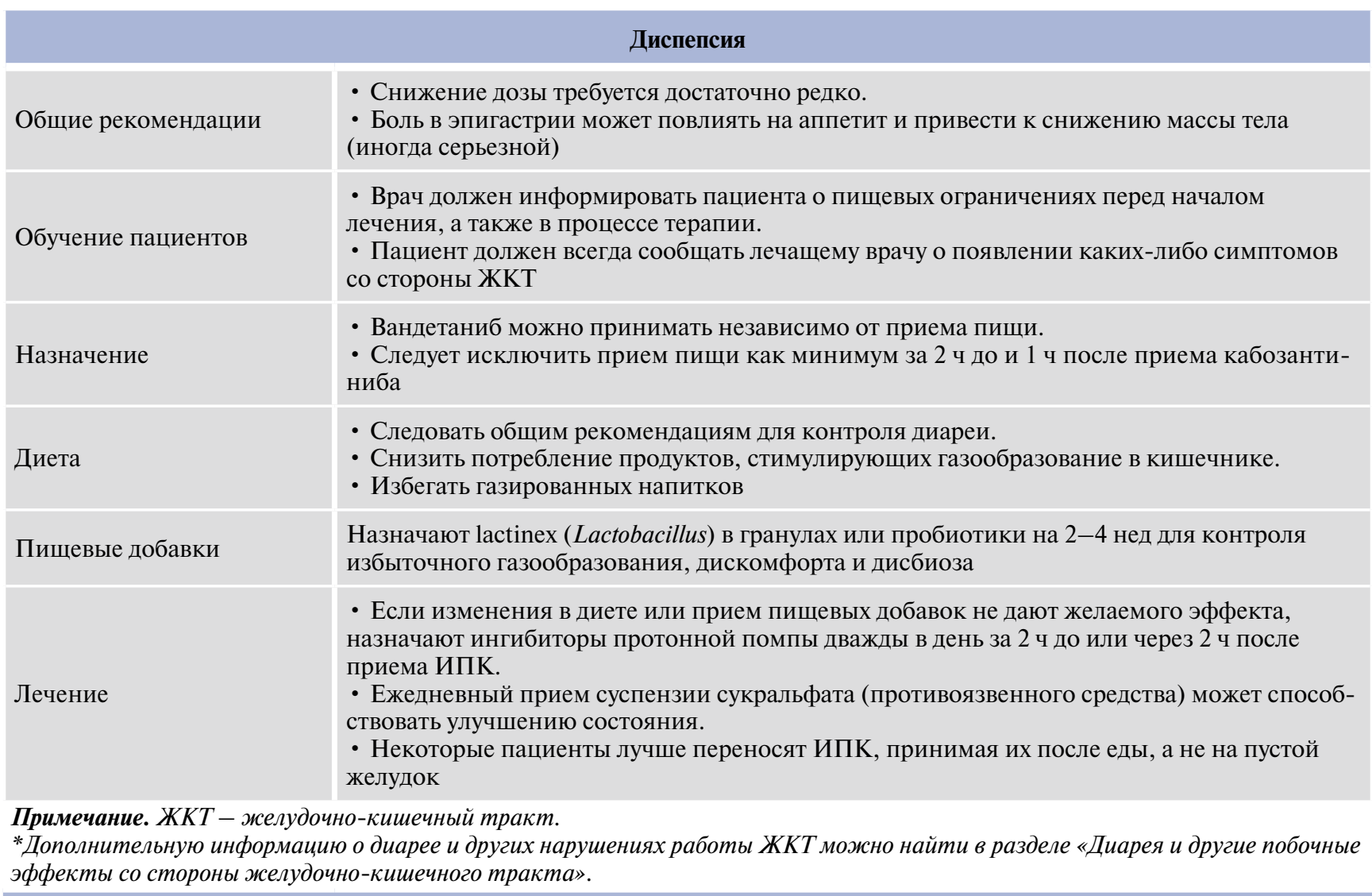

тяжесть диареи и назначить соответствующее лечение. При тяжелой диарее (III-IV степени тяжести) рекомендуется временно прервать терапию ИПК до нормализации состояния и затем снизить дозу [17]. Пациентам с тяжелой диареей и высоким риском обезвоживания может потребоваться внутривенная регидратация в амбулаторных условиях. Кроме того, такие больные нуждаются в тщательном мониторинге (включающем элктрокардиографию и определение концентрации электролитов в сыворотке) с целью раннего выявления и коррекции потенциально опасных побочных эффектов ИПК [20].

Лечение диареи проводят путем временной отмены ИПК, снижения дозы, а также назначения специальных препаратов (см. табл. 5) [11, 21]. У пациентов, которые изначально не имели ассоциированной с основным заболеванием диареи, лечение вандетанибом чаще вызывает диарею I степени тяжести, а лечение кабозантинибом - диарею II степени тяжести. Легкая и умеренная диарея обычно легко контролируется путем регулярного приема лоперамида [20]. Рекомендации по изменению диеты (например, прием пробиотиков и отказ от пищи с высоким содержанием пищевых волокон) чаще всего недостаточны.

\section{Воспаление слизистой оболочки u стоматum/боль в полостu pma npu npueме кабозантиниба}

Кабозантиниб и другие ИПК способны, кроме всего прочего, провоцировать развитие воспалений слизистой оболочки и стоматита/боли в полости рта, что связано с ингибированием VEGFR/EGFR [19]. В клиническом испытании кабозантиниба у 29 \% пациентов с распространенным МРЩЖ наблюдался стоматит различной степени тяжести (у 1,9\% - III-IV степени), а у $23 \%$ участников - мукозит (у $3 \%$ - III-IV степени тяжести) [8]. В инструкции к кабозантинибу указано, что $36 \%$ пациентов предъявляли жалобы на боль в полости рта различной степени тяжести [7]. Побочные эффекты со стороны ротовой полости обычно развиваются в течение 2-4 нед после начала терапии. Для купирования боли в полости рта используют раствор соли и бикарбоната натрия, ополаскиватели, содержащие сукральфат и/или лидокаин [11]. Некоторым пациентам помогает использование ополаскивателей, содержащих экстракт алоэ вера, отказ от кислых и пряных продуктов, ароматизированных зубных паст. Побочные эффекты, связанные с воспалением слизистой оболочки полости рта, не наблюдались среди участников исследования вандетаниба III фазы, поэтому информация о них отсутствует в инструкции к препарату [6, 9]. 


\section{Дерматологические побочные эффекты}

Вандетаниб. Прием ИПК часто сопровождается дерматологическими побочными эффектами, что, по-видимому, связано (по крайней мере, частично) с ингибированием VEGFR и EGFR [19]. Пациенты, принимавшие вандетаниб в рамках клинического испытания, предъявляли жалобы на сыпь (45 \%), акне (20\%), сухость кожи (15\%), акнеподобный дерматит (15\%). Чаще всего эти побочные эффекты были I или II степени тяжести, однако у 4 \% пациентов была зарегистрирована сыпь III-IV степени тяжести [9]. Тяжелые кожные реакции, такие как синдром Стивенса-Джонсона и токсический эпидермальный некролиз, наблюдались при приеме вандетаниба, но не в рамках клинических испытаний [6, 9]. Если тяжелые кожные реакции не поддаются лечению системными кортикостероидами, следует отменить вандетаниб [6]. Менее тяжелые реакции можно лечить топическими анальгетиками (например, лидокаином); необходима поддерживающая терапия. Превентивное увлажнение кожи снижает вероятность развития кожных реакций [11].

Кабозантиниб. В клиническом испытании кабозантиниба примерно у половины пациентов наблюдалась ЛПЭ/ЛПС разной степени тяжести, а в $13 \%$ случаев была зафиксирована тяжелая ЛПЭ/ЛПС [8]. Поскольку первые симптомы ЛПЭ/ЛПС могут появиться уже через несколько недель после начала лечения ИПК, то превентивные меры в данном случае вполне оправданны [7, 8, 11]. Помимо ЛПЭ/ЛПС, прием кабозантиниба может вызывать такие кожные реакции, как сыпь, сухость кожи, алопеция, эритема и гиперкератоз $[7,8]$.

Лечение. Подробные рекомендации по лечению дерматологических побочных эффектов представлены в табл. 6 [6, 7, 11, 17]. Проявления ЛПЭ могут быть быстро купированы приемом ибупрофена каждые 8 ч в течение длительного времени. Важно отметить, что в большинстве случаев наблюдается постепенное прогрессирование ЛПЭ I и II степени тяжести до III степени, следовательно, раннее назначение адекватной терапии позволит предотвратить тяжелые эффекты, требующие отмены препарата и снижения его дозы. Избирательное применение лосьонов с глюкокортикостероидами (например, крема с 0,05 \% триамцинолона) может облегчить симптомы раздражения кожи рук [11]. В случае отсутствия терапевтического эффекта у пациентов с побочными эффектами III степени тяжести (или плохо переносимыми II степени тяжести) требуется временная отмена препарата. Лечение возобновляют после улучшения (снижения тяжести до І степени), но применяют меньшие дозы [7].

Важно отметить, что у пациентов могут развиться светочувствительность и кожные реакции, провоцируемые воздействием солнечного света (фотодерматит) [6]. Следовательно, необходимо объяснить пациентам важность избегания прямых солнечных лучей, рекомендовать носить одежду, защищающую от солнца и пользоваться солнцезащитными кремами [11]. Как и при других побочных эффектах, 19-дневный период полувыведения вандетаниба значительно задерживает нивелирование кожных токсических

Таблица 6. Рекомендации по профилактике и лечению ладонно-подошвенной эритродизестезии/ладонно-подошвенных кожных реакций (ЛПЭ/ЛПС) и других кожных нарушений, вызываемых вандетанибом и кабозантинибом [5, 6, 10, 16]*

\section{Общие рекомендации}

\begin{tabular}{|c|c|}
\hline \multicolumn{2}{|r|}{ Общие рекомендации } \\
\hline Перед началом лечения & $\begin{array}{l}\text { - Первичное обследование на предмет наличия гиперкератоза. } \\
\text { • Обучение пациента способам профилактики и лечения. } \\
\text { • Увлажнение кожи: частое (дважды в день) нанесение гипоаллергенных смягчающих } \\
\text { средств/кремов без отдушек на кожу рук, ног и другие сухие участки. } \\
\text { - Контроль возникновения мозолей (маникюр/педикюр). } \\
\text { • Использование кератолитических средств (кремов на основе } 20-40 \text { \% мочевины дважды } \\
\text { в день) для отшелушивания мозолей. } \\
\text { - Защита подвергающихся давлению и нежных участков стоп: мягкая и удобная обувь, } \\
\text { стельки с подушечками, подошвы из ударопоглощающих материалов }\end{array}$ \\
\hline $\begin{array}{l}\text { В ходе лечения (любая } \\
\text { степень тяжести) }\end{array}$ & $\begin{array}{l}\text { • Продолжить следовать рекомендациям, представленным выше. } \\
\text { • Еженедельно осматривать пациента в течение первых } 6 \text { нед лечения. } \\
\text { • Избегать горячей воды. } \\
\text { • Вытирать руки после мытья. } \\
\text { • Надевать толстые хлопчатобумажные перчатки и носки после нанесения смягчающих } \\
\text { средств (в том числе на ночь) для предотвращения дальнейшего травмирования кожи } \\
\text { и сохранения в ней влаги. } \\
\text { • Делать прохладные ванночки для ног с сульфатом магния, чтобы уменьшить боль } \\
\text { и размягчить мозоли. } \\
\text { • Избегать пребывания на солнце, так как ингибиторы протеинкиназ являются } \\
\text { фотосенсибилизаторами. } \\
\text { • Избегать переохлаждения, особенно кистей и стоп }\end{array}$ \\
\hline
\end{tabular}


Окончание табл. 6

\begin{tabular}{|c|c|c|}
\hline В зависимости от тяжести & Первичное лечение & Дальнейшие подходы (по мере необходимости) \\
\hline $\begin{array}{l}\text { I степень тяжести } \\
\text { (легкие): минимальные } \\
\text { кожные реакции } \\
\text { или дерматит (например, } \\
\text { эритема) без боли }\end{array}$ & $\begin{array}{l}\text { • Продолжать следовать рекомендаци- } \\
\text { ям, представленным выше. } \\
\text { • Наблюдение в течение } 2 \text { нед. } \\
\text { • Ибупрофен в дозе } 600 \text { мг трижды } \\
\text { в день }\end{array}$ & $\begin{array}{l}\text { • Рассмотреть возможность топической терапии } \\
\text { для облегчения симптомов. } \\
\text { • Не менять дозу ингибиторов протеинкиназ }\end{array}$ \\
\hline $\begin{array}{l}\text { II степень тяжести } \\
\text { (умеренные): кожные } \\
\text { реакции (например, } \\
\text { шелушение, волдыри, } \\
\text { кровотечение, отек) } \\
\text { с болью, не влияющей } \\
\text { на функции }\end{array}$ & $\begin{array}{l}\text { • Продолжать следовать рекомендаци- } \\
\text { ям, указанным в разделе «В ходе лече- } \\
\text { ния»; ибупрофен в дозе } 600 \text { мг трижды } \\
\text { в день. } \\
\text { • Наблюдение в течение } 1 \text { нед. } \\
\text { • Нанесение клобетазола или триамци- } \\
\text { нолона (0,05 \% крем) на эритематозные } \\
\text { участки } 4 \text { раза в день. } \\
\text { - Топические анальгетики (например, } \\
2 \text { \% лидокаин) для обезболивания }\end{array}$ & $\begin{array}{l}\text { Вандетаниб: побочные эффекты II степени } \\
\text { тяжести не описаны в инструкции к препарату. } \\
\text { Кабозантиниб: } \\
\text { • в случае отсутствия улучшений } \\
\text { при выполнении описанных рекомендаций } \\
\text { препарат временно отменяют до облегчения } \\
\text { симптомов ладонно-подошвенной } \\
\text { эритродизестезии (снижения тяжести } \\
\text { со II и III степени до I степени); } \\
\text { • лечение пробуют возобновить в той же дозе, } \\
\text { но если возникает рецидив ладонно- } \\
\text { подошвенной эритродизестезии либо у пациента } \\
\text { наблюдалась ладонно-подошвенная } \\
\text { эритродизестезия III степени тяжести, то дозу } \\
\text { снижают }\end{array}$ \\
\hline $\begin{array}{l}\text { III степень тяжести } \\
\text { (тяжелые): язвенный } \\
\text { дерматит или изменения } \\
\text { кожи с болью, которая } \\
\text { влияет на функции }\end{array}$ & $\begin{array}{l}\text { • Продолжать следовать рекомендаци- } \\
\text { ям, указанным в разделе «В ходе лече- } \\
\text { ния». } \\
\text { • Наблюдение в течение } 1 \text { нед. } \\
\text { • Топическая терапия для облегчения } \\
\text { симптомов (кремы с кортизоном). } \\
\text { • Системная терапия для облегчения } \\
\text { симптомов (например, пиридоксин } \\
\text { в дозе } 50-150 \text { мг/сут) }\end{array}$ & $\begin{array}{l}\text { Вандетаниб: } \\
\text { • снизить дозу с } 300 \text { до } 200 \text { мг/сут, а затем } \\
\text { до } 100 \text { мг/сут; } \\
\text { • временно отменить препарат при побочных } \\
\text { эффектах III-IV степени тяжести вплоть } \\
\text { до улучшения (снижения тяжести } \\
\text { с III до I степени); } \\
\text { • возобновить лечение с использованием } \\
\text { меньшей дозы; } \\
\text { • в случае рецидивирующих побочных } \\
\text { эффектов снизить дозу до } 100 \text { мг/сут } \\
\text { до их исчезновения или снижения их тяжести } \\
\text { до І степени, если продолжение лечения } \\
\text { оправданно; } \\
\text { • в случае тяжелых кожных реакций направить } \\
\text { пациента на срочную консультацию; } \\
\text { • системная терапия (например, } \\
\text { кортикостероидами) может быть уместна; } \\
\text { • рекомендуется полная отмена вандетаниба. } \\
\text { Кабозантиниб: } \\
\text { • временно отменить препарат при побочных } \\
\text { эффектах III-IV степени тяжести } \\
\text { или непереносимых эффектах II степени } \\
\text { тяжести вплоть до улучшения (снижения } \\
\text { тяжести с III до I степени); } \\
\text { • возобновить лечение с использованием } \\
\text { меньшей дневной дозы: } \\
\text { - } 100 \text { мг вместо } 140 \text { мг, } \\
\text { - } 60 \text { мг вместо } 100 \text { мг, } \\
\text { - } 60 \text { мг - дозу далее не снижают (если пациент } \\
\text { переносит) либо полностью отменяют препарат }\end{array}$ \\
\hline
\end{tabular}

реакций [6]. Следовательно, пациенты должны избегать пребывания на солнце и продолжать использовать солнцезащитный крем в течение 4 мес после отмены вандетаниба [6].
Кровотечения, перфорации, свищи и заживление ран

Вандетаниб. ИПК имеют ряд потенциально опасных побочных эффектов со стороны ЖКТ, что обусловлено их антиангиогенной активностью из-за 
ингибирования VEGFR. Помимо описанных ранее побочных эффектов со стороны ротовой полости, к ним также относят кровотечения, перфорации кишечника, свищи (как в органах ЖКТ, так и в других, например, в трахее) $[6,7,19]$. Несмотря на то что ни у одного из пациентов в клиническом исследовании III фазы не было зафиксировано серьезных кровотечений или перфорации кишечника, прием вандетаниба все же вызывал незначительные и умеренные кровотечения у $14 \%$ больных, а также перфорацию кишечника у нескольких пациентов $(0,4 \%)[6,9]$. По нашему опыту, риск перфорации кишечника при приеме ИПК выше у лиц с заболеваниями кишечника в анамнезе (колитом или дивертикулитом).

Кабозантиниб. В инструкции к кабозантинибу содержится специальное предупреждение о том, что препарат способен вызвать кровотечения в ЖКТ, и не только из-за ингибирования VEGFR [7]. Тяжелые и даже смертельные кровотечения были зафиксированы у 3 \% пациентов, получавших кабозантиниб. Тяжелые случаи перфорации кишечника наблюдались у 3 \% пациентов, свищи - у 1 \% (1 летальный случай). Были также летальные случаи свищей трахеи/пищевода [7].

Лечение. Из-за высокого риска тяжелых и даже опасных для жизни побочных эффектов кабозантиниб противопоказан пациентам с недавними кровотечениями и кровохарканьем. У больных, уже получающих препарат, необходимо особо тщательно мониторировать появление симптомов, которые могут указывать на перфорацию кишечника и появление фистул $[7,8]$. Прием ИПК повышает риск перфорации в местах, ранее подвергавшихся хирургическому лечению (местах анастомоза) или лучевой терапии [11]. При возникновении перфорации лечение следует прекратить и организовать тщательное наблюдение за пациентом, чтобы установить, нуждается ли он в реконструктивной хирургии. Еще одним побочным эффектом кабозантиниба является плохое заживление ран вследствие ухудшения кровообрашения $[11,19]$. По соображениям безопасности препарат следует отменить минимум за 2-4 нед до серьезной операции (и за 10 дней до любой операции) в зависимости от периода полувыведения. После хирургического вмешательства лечение можно возобновить после клинической оценки темпов заживления раны. Следует, однако, отметить, что у пациентов, которым потребовалась экстренная операция (а значит, у которых препарат предварительно не отменяли), серьезных кровотечений зафиксировано не было [11].

\section{Утомляемость}

Повышенная утомляемость - достаточно распространенный побочный эффект ИПК. Утомляемость наблюдалась не менее чем у 40 \% участников клинических испытаний вандетаниба (у $24 \%$ - любой степени тяжести, у $6 \%$ - тяжелая) и кабозантиниба (у $41 \%$ - любой степени тяжести, у $9 \%$ - тяжелая) [8, 9]. Утомляемость, возникнув в первые месяцы терапии, может в дальнейшем исчезнуть без каких-либо дополнительных вмешательств [11]; однако чаще всего это персистирующий побочный эффект, который может причинять пациенту значительные неудобства и даже приводить к инвалидности. Следует внимательно проанализировать факторы, которые могут вносить вклад в развитие этого побочного эффекта, в том числе психоэмоциональный дистресс/депрессия, потеря мышечной массы, диарея, обезвоживание, боль, плохое питание, дисбаланс жидкости и электролитов, гипотиреоз и другие сопутствующие заболевания [11, 24]. Для купирования повышенной утомляемости обычно рекомендуют изменение режима дня, прием ИПК вечером (чтобы минимизировать дневную утомляемость), потребление кофеина (если нет диареи), физические упражнения (особенно силовые упражнения, помогающие поддерживать мышечную массу), контроль уровня электролитов и ТТГ. Тем не менее некоторым пациентам все же требуется снижение дозы [11].

ИПК могут усугублять течение гипотиреоза. По крайней мере $90 \%$ пациентов в клинических исследованиях вандетаниба и кабозантиниба III фазы ранее подвергались тиреоидэктомии; у $49 \%$ пациентов, принимавших вандетаниб, и 57 \% пациентов, принимавших кабозантиниб, наблюдалось повышение уровня ТТГ, что требовало дополнительной заместительной терапии [6-9]. Таким образом, требуется мониторинг концентраций ТТГ и $\mathrm{T}_{4}$ в сыворотке крови через 2-4 мес, затем через 8-12 мес после начала терапии, затем каждые 3 мес. Заместительная терапия при гипотиреозе должна корректироваться по мере необходимости, если повышение уровня ТТГ указывает на ухудшение [6].

\section{Дополнительные рекомендации}

Пациенты с распространенным МРЩЖ должны по возможности проходить лечение под наблюдением специалиста по раку щитовидной железы с опытом лечения МРЩЖ, желательно также при поддержке команды специалистов в разных областях медицины, в том числе эндокринологии, терапевтической онкологии, радиационной онкологии, интервенционной радиологии, патологии, дерматологии и паллиативной помощи. Онкологи местных медицинских учреждений могут обрашаться за консультацией к коллегам, работающим в более крупных специализированных центрах, если это необходимо, чтобы улучшить лечение пациентов на местах. Для некоторых пациентов вопрос об уместности назначения ИПК и сроке их назначения будет решить особенно сложно. K ним относятся пожилые или ослабленные пациенты (с оценкой $>2$ баллов по шкале Восточной 
объединенной онкологической группы (Eastern Cooperative Oncology Group)), пациенты с низкой массой тела, сопутствующими заболеваниями (которые повышают риск развития побочных эффектов), подвергавшиеся хирургическому лечению или лучевой терапии, кандидаты на проведение хирургического лечения, а также больные, принимающие препараты, взаимодействующие с вандетанибом и кабозантинибом (например, сильные индукторы СҮРЗА4).

Консультирование и обучение пациентов очень важны для составления эффективного плана лечения, ориентированного на пациента, который обязательно участвует в принятии важных решений. Возможные риски, ассоциированные с МРЩЖ, и риски терапии должны быть тщательно взвешены с учетом целей лечения каждого отдельного пациента. Принимая решение о лечении, пациент должен осознавать риск побочных эффектов и быть готовым к токсическим реакциям, а также понимать, что активное наблюдение без лечения тоже несет определенные риски. Обучение пациентов помогает им преодолеть страх токсических реакций, который может препятствовать своевременному началу терапии. Тесное общение врача, медсестры и пациента поможет быстро диагностировать побочный эффект при его первом появлении, что создает возможности для проведения профилактических мероприятий, целью которых является поддержание высокой приверженности к лечению и хорошей переносимости терапии.

\section{Выводы и дальнейшие указания}

Клинические рекомендации по лечению распространенного МРЩЖ не содержат указаний по выбору конкретного ИПК для первичной системной терапии, а также для дальнейшего лечения при прогрессировании заболевания. Солитарные прогрессирующие опухоли можно лечить с помощью локальных методов, в том числе радиочастотной абляции, криоабляции, хирургического вмешательства или лучевой терапии, которые, возможно, позволят продолжить терапию ИПК после прогрессирования и добиться клинического эффекта [1].

Чтобы достичь наилучшего результата, авторы рекомендуют менять один ИПК на другой в процессе лечения (вандетаниб на кабозантиниб или наоборот). Кроме того, дополнительную пользу может принести возврат к препаратам, которые использовались до прогрессирования заболевания. После развития резистентности к обоим препаратам пациенту настоятельно рекомендуется принять участие в клиническом испытании (если есть возможность), перед тем как начинать лечение не по инструкции. Неофициальные отчеты указывают на то, что у пациентов с прогрессированием опухоли на фоне терапии каким-то ИПК может наблюдаться положительная динамика или стабилизация состояния в ответ на применение другого ИПК или комбинации нескольких ИПК.

Некоторые другие препараты также продемонстрировали свою эффективность в отношении МРЩЖ и иногда использовались не по инструкции в практике авторов. Сюда относятся сунитиниб (Сутент $\left.{ }^{\circledR}\right)$, сорафениб (Нексавар $\left.{ }^{\circledR}\right)$, пазопаниб (Вотриент $\left.{ }^{\circledR}\right)$, довитиниб, ленватиниб (Ленвима $\left.{ }^{\circledR}\right)$, цитотоксическая химиотерапия на основе дакарбазина (например, циклофосфамид, винкристин, дакарбазин (CVD)), пероральный дакарбазин, темозоломид (темодар ${ }^{\circledR}$ ) [1, 25-31]. В отдельных случаях прогрессирующего, но вялотекущего МРЩЖ октреотид (сандостатин ${ }^{\circledR}$ ) или ланреотид (соматулин ${ }^{\circledR}$ ) могут замедлить прогрессирование заболевания [1, 32]. Если основные проявления заболевания удается держать под контролем, но некоторые из них прогрессируют, следует рассмотреть возможность терапии ИПК совместно с направленными/фокальными средствами или усилением системной терапии. Антирезорбтивная терапия важна для пациентов с прогрессирующими болезнями костей, а радиотерапия и/или термическая абляция могут быть эффективны при очаговых прогрессирующих или симптоматических поражениях костей [1].

Распространенный МРЩЖ создает значительную потребность в новых эффективных препаратах, по мере того как завершаются клинические исследования вандетаниба и кабозантиниба. В настоящее время находятся в разработке новые, более мощные селективные ингибиторы тирозинкиназы RET и ингибиторы других мишеней и сигнальных путей, критически важных для прогрессирования МРЩЖ [33]. Геномика и персональное секвенирование генома также могут быть в конечном счете использованы для идентификации специфических мутаций (не $R E T$ ) у пациентов с МРЩЖ. Эти мутации станут объектом таргетной терапии (например, HRAS) [34, 35]. Хотя используемые сейчас препараты активны как у пациентов с мутациями RET, так и без них, для назначения новых, изучаемых в настоящее время средств (которые более специфичны для мутаций $R E T$ и не обладают активностью в отношении VEGFR) у всех пациентов без герминативных мутаций RET может потребоваться исследование опухолей с помощью генетического секвенирования с целью выявления соматических молекулярных изменений (для таргетной терапии). Кроме того, продолжается изучение методов лечения, отличных от традиционных, с использованием низкомолекулярных препаратов, способных вызвать иммунный ответ у пациентов с МРЩЖ (включая вакцины, специфичные для опухоли, и ингибиторы иммунных контрольных точек) [36, 37].

В заключение следует отметить, что широкий диапазон токсических эффектов ИПК и их потенциальная тяжесть диктуют необходимость тщатель- 
ного наблюдения за пациентами, а также раннего выявления побочных эффектов и быстрого принятия мер по их устранению. При своевременном и эффективном поддерживающем лечении и коррекции доз по мере необходимости большинство пациентов с распространенным МРШЖ смогут продолжать лечение и получать максимальную пользу от приема препаратов, хотя МРЩЖ считается в настоящее время неизлечимой злокачественной опухолью.

\section{$\begin{array}{lllllllllllllllllllll}\text { Л } & \text { И } & \text { I } & \text { E } & \text { P } & \text { A } & \text { I } & \text { V } & \text { P } & \text { A } & \text { I } & \text { R } & \text { E } & \text { F } & \text { E } & \text { R } & \text { E } & \text { N } & \text { G } & \text { E } & S\end{array}$}

1. Referenced with permission from the NCCN clinical practice guidelines in oncology (NCCN Guidelines ${ }^{\circledR}$ ) for thyroid carcinoma, v. 2.2017. (C) National Comprehensive Cancer Network, Inc. 2017. All rights reserved. Accessed June 16, 2017. To view the most recent and complete version of the guideline, go online to NCCN.org. National Comprehensive Cancer Network ${ }^{\circledR}, \mathrm{NCCN} \AA$, $\mathrm{NCCN}$ guidelines ${ }^{\circledR}$, and all other NCCN content are trademarks owned by the National Comprehensive Cancer Network Inc.

2. Wells S.A. Jr, Asa S.L., Dralle H. et al. American thyroid association guidelines task force on medullary thyroid carcinoma. Revised American Thyroid Association guidelines for the management of medullary thyroid carcinoma. Thyroid 2015;25(6):567-610. DOI: 10.1089 /thy.2014.0335.

3. Smit J. Treatment of advanced medullary thyroid cancer. Thyroid Res 2013;6(Supp 1): S7. DOI: 10.1186/1756-6614-6-S1-S7.

4. Randle R.W., Balentine C.J., Leverson G.E. et al. Trends in the presentation, treatment, and survival of patients with medullary thyroid cancer over the past 30 years. Surgery 2017;161(1):137-46. DOI: 10.1016/j. surg.2016.04.053.

5. Roy M., Chen H., Sippel R.S. Current understanding and management of medullary thyroid cancer. Oncologist 2013;18(10):1093-100.

6. Caprelsa ${ }^{\circledR}$ (vandetanib) tablets for oral use [prescribing information]. Cambridge, MA: Sanofi Genzyme, 2016.

7. Cometriq ${ }^{\circledR}$ (cabozantinib) capsules, for oral use [prescribing information]. South San Francisco, CA: Exelixis, Inc., 2016.

8. Elisei R., Schlumberger M.J., Müller S.P. et al. Cabozantinib in progressive medullary thyroid cancer. J Clin Oncol 2013;31(29):3639-46. DOI: 10.1200/ JCO.2012.48.4659.

9. Wells S.A. Jr, Robinson B.G., Gagel R.F. et al. Vandetanib in patients with locally advanced or metastatic medullary thyroid cancer: a randomized, double-blind phase III trial. J Clin Oncol 2012;30(2):134-41.

10. Yakes F.M., Chen J., Tan J. et al. Cabozantinib (XL184), a novel MET and VEGFR2 inhibitor, simultaneously suppresses metastasis, angiogenesis, and tumor growth. Mol Cancer Ther 2011;10(12):2298-308. DOI: 10.1158/1535-7163.MCT-11-0264.
11. Brose M.S., Frenette C.T., Keefe S.M., Stein S.M. Management of sorafenib-related adverse events: a clinician's perspective. Semin Oncol 2014;41(Suppl 2):S1-16. DOI: 10.1053/j.seminoncol.2014.01.001.

12. Holden S.N., Eckhardt S.G., Basser R. et al. Clinical evaluation of ZD6474, an orally active inhibitor of VEGF and EGF receptor signaling, in patients with solid, malignant tumors. Ann Oncol 2005;16(8):1391-7.

13. ClinicalTrials.gov. To compare the effects of two doses of vandetanib in patients with advanced medullary thyroid cancer. ClinicalTrials.gov Identifier: NCT01496313, https://clinicaltrials.gov/ [accessed 06.16.17].

14. Haddad R.I. How to incorporate new tyrosine kinase inhibitors in the treatment of patients with medullary thyroid cancer. J Clin Oncol 2013;31(29):3618-20. DOI: $10.1200 / J C O .2013 .51 .5098$.

15. ClinicalTrials.gov. A study of two different doses of cabozantinib (XL184) in progressive, metastatic medullary thyroid cancer (EXAMINER). ClinicalTrials.gov Identifier: NCT01896479, https://clinicaltrials. gov/ [accessed 06.16.17].

16. Lenihan D.J., Kowey P.R. Overview and management of cardiac adverse events associated with tyrosine kinase inhibitors. Oncologist 2013;18(8):900-8. DOI: 10.1634/theoncologist.2012-0466.

17. Caprelsa ${ }^{\circledR}$ REMS program. Risk evaluation and mitigation strategy. Welcome to the CAPRELSA REMS program, http://www.caprelsarems.com; December 2013 [accessed 06.16.17].

18. Moslehi J.J. Cardiovascular toxic effects of targeted cancer therapies. N Engl J Med 2016;375(15):1457-67.

19. Dy G.K., Adjei A.A. Understanding, recognizing, and managing toxicities of targeted anticancer therapies. CA Cancer J Clin 2013;63(4):249-79. DOI: 10.3322/ caac. 21184

20. Huo Z., Yu S., Hong S. et al. A systematic review and meta-analysis of the risk of diarrhea associated with vandetanib treatment in carcinoma patients. Onco Targets Ther 2016;2016(9):3621-31. DOI: $10.2147 /$ OTT.S96830.

21. Benson A.B. 3rd, Ajani J.A., Catalano R.B. et al. Recommended guidelines for the treatment of cancer treatment-induced diarrhea. J Clin Oncol 2004;22(14): 2918-26.
22. National Cancer Institute. Gastrointestinal complications (PDQ $\left.{ }^{\circledR}\right)$-health professional version. Diarrhea. https://www.cancer. gov/about-cancer/treatment/sideeffects/ constipation/GI-complications-hppdq\#section/_119; May 2017 [accessed 06.16.17]

23. Imodium ${ }^{\circledR}$ (loperamide hydrochloride) [prescribing information]. Johnson \& Johnson Consumer Inc., McNeil Consumer Healthcare Division; October 2016.

24. Referenced with permission from the $\mathrm{NCCN}$ clinical practice guidelines in oncology (NCCN Guidelines ${ }^{\circledR}$ ) for cancerrelated fatigue, v. 2.2017. (C) National Comprehensive Cancer Network, Inc. 2017. All rights reserved. Accessed June 16, 2017. To view the most recent and complete version of the guideline, go online to NCCN. org. National Comprehensive Cancer Network ${ }^{\circledR}, \mathrm{NCCN} \circledast$, $\mathrm{NCCN}$ guidelines ${ }^{\circledR}$, and all other NCCN Content are trademarks owned by the National Comprehensive Cancer Network Inc.

25. Ravaud A., de la Fouchardière C., Asselineau J. et al. Efficacy of sunitinib in advanced medullary thyroid carcinoma: intermediate results of phase II THYSU. Oncologist 2010;15(2):212-3. DOI: 10.1634/theoncologist.2009-0303.

26. Capdevila J., Iglesias L., Halperin I. et al. Sorafenib in metastatic thyroid cancer. Endocr Relat Cancer 2012;19(2):209-16. DOI: 10.1530/ERC-11-0351.

27. Bible K.C., Suman V.J., Molina J.R. et al. Endocrine malignancies disease oriented group, mayo clinic cancer center, and the mayo Phase 2 Consortium. A multicenter phase 2 trial of pazopanib in metastatic and progressive medullary thyroid carcinoma: MC057H. J Clin Endocrinol Metab 2014;99(5):1687-93. DOI: 10.1210/ jc. 2013-3713.

28. Lim S.M., Chung W.Y., Nam K.H. et al. An open label, multicenter, phase II study of dovitinib in advanced thyroid cancer. Eur J Cancer 2015;51(12):1588-95. DOI: 10.1016/j.ejca.2015.05.020.

29. Schlumberger M., Jarzab B., Cabanillas M.E. et al. A phase II trial of the multitargeted tyrosine kinase inhibitor lenvatinib (E7080) in advanced medullary thyroid cancer. Clin Cancer Res 2016;22(1):44-53. DOI: 10.1158/1078-0432.CCR-15-1127.

30. Marchand L., Nozières C., Walter T. et al. Combination chemotherapy with 5 -fluoro- 
uracil and dacarbazine in advanced medullary thyroid cancer, a possible alternative? Acta Oncol 2016;55(8):1064-6. DOI: 10.3109/0284186X.2016.1157264.

31. Deutschbein T., Matuszczyk A., Moeller L.C. et al. Treatment of advanced medullary thyroid carcinoma with a combination of cyclophosphamide, vincristine, and dacarbazine: a single-center experience. Exp Clin Endocrinol Diabetes 2011;119(9):540-3. DOI: $10.1055 / \mathrm{s}-0031-1279704$

32. Vitale G., Tagliaferri P., Caraglia M. et al. Slow release lanreotide in combination with interferon-alpha $2 b$ in the treatment of symptomatic advanced medullary thyroid carcinoma. J Clin Endocrinol Metab 2000;85(3):983-8.

33. ClinicalTrials.gov. Trial of LBH589 in metastatic thyroid cancer. ClinicalTrials.gov Identifier: NCT01013597, https://clinicaltrials.gov/. [accessed 06.16.17].

34. ClinicalTrials.gov. Personalized cancer therapy for patients with metastatic medullary thyroid cancer. ClinicalTrials. gov Identifier: NCT02363647, https:// clinicaltrials.gov/. [accessed 01.19.17].

35. ClinicalTrials.gov. Phase II study of tipifarnib in squamous head and neck can- cer with HRAS mutations. ClinicalTrials.gov Identifier: NCT02383927, https://clinicaltrials.gov/. [accessed 06.16.17].

36. ClinicalTrials.gov. GI6207 for advanced medullary thyroid cancer. ClinicalTrials. gov Identifier: NCT01856920, https://clinicaltrials.gov/ [accessed 06.16.17].

37. ClinicalTrials.gov. Study of pembrolizumab (MK3475) in participants with advanced solid tumors (MK3475158/KEY-

NOTE158). ClinicalTrials.gov Identifier: NCT02628067, https://clinicaltrials.gov/ [accessed 06.16.17].

Благодарность. Авторы благодарят Cricket Darby, PhD, из компании Connexion Healthcare (Ньютаун, Пенсильвания) за помощь при написании статьи; конфликт интересов отсутствует. Редактирование и дизайн статьи также выполнены Connexion Healthcare.

Финансирование. Исследование проведено без спонсорской поддержки.

Конфликт интересов. Marcia Brose, Keith C. Bible, Laura Q. M. Chow, Jill Gilbert и Carolyn Grande являются консультантами Sanofi Genzyme. Robert I. Haddad получал поддержку исследования от Merck, Bristol-Myers Squibb, Celgene, AstraZeneca и Pfizer и является консультантом Sanofi Genzyme, Merck, AstraZeneca, Eisai, Bristol-Myers Squibb, Pfizer и Celgene.

Francis. Worden получал финансовую поддержку в качестве заместителя главного исследователя и участника заседаний консультативного совета от Merck, в качестве заместителя главного исследователя - от Bristol-Myers Squibb, в качестве участника заседаний консультативного совета - от Genzyme. 